\title{
When and how to perform the provisional approach for distal LM stenting
}

\author{
Seung-Jung Park ${ }^{1 *}$, MD, PhD; Jung-Min Ahn, MD; Nicolas Foin², MSc, PhD; Yves Louvard³, MD \\ 1. Heart Institute, Asan Medical Center, University of Ulsan College of Medicine, Seoul, South Korea: 2. National Heart Centre \\ Singapore, Singapore; 3. Institut Cardiovasculaire Paris Sud, Massy, France
}

The references can be found in the online version of this paper at the following website: http://www.pcronline.com/eurointervention/V_issue/27

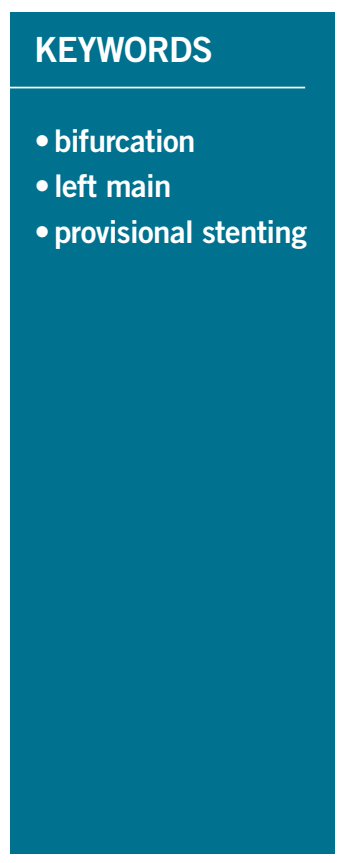

\begin{abstract}
Despite the tremendous developments that have been made in the field of interventional cardiology over the past few decades, the percutaneous treatment of left main (LM) bifurcation still remains challenging. The provisional one-stent approach for LM bifurcation showed more favourable outcomes compared to the double-stenting technique. Consequently, it has been the preferred strategy in the majority of LM bifurcation stenosis. However, due to the large myocardial burden of the side branch, the risk of haemodynamic collapse after main vessel stenting has always existed. To reduce the risk of side branch occlusion and for proper selection of this strategy, it is acknowledged that meticulously performed IVUS evaluation of the side branch ostium is helpful. A fractional flow reserve measurement of the angiographically jailed side branch could also lead to the avoidance of an unnecessary complex intervention. However, as the overall data were derived from observational studies, further larger randomised trials would be necessary to assess the optimal provisional one-stent strategy for LM bifurcation.
\end{abstract}

\footnotetext{
*Corresponding author: Department of Cardiology, University of Ulsan College of Medicine, Asan Medical Center, 388-1 Poongnap-dong, Songpa-gu, Seoul, 138-736, Republic of Korea.E-mail: sjpark@amc.seoul.kr
} 


\section{Introduction}

Based on the results from randomised trials and observational studies, percutaneous coronary intervention (PCI) for unprotected left main (LM) coronary artery stenosis is considered as a potential alternative to bypass surgery ${ }^{1}$. However, PCI for LM bifurcation was technically demanding and was associated with a high rate of adverse clinical events ${ }^{2}$. In addition, the lack of randomised clinical trials has often led to a controversy on the optimal stenting strategy for LM bifurcation. In this review, we discuss when and how to perform the provisional approach for the treatment of LM bifurcation stenosis.

\section{Outcomes of the provisional approach for distal LM bifurcation}

The provisional approach is a single-stent strategy but allows the positioning of a second stent, if required (Figure 1). Similarly to non-LM bifurcation, the provisional one-stent approach for distal LM bifurcation was associated with a lower risk of major adverse cardiac events $^{3-5}$, death ${ }^{5}$, myocardial infarction ${ }^{4,5}$, and target vessel revascularisation ${ }^{4-6}$ compared to the double stenting technique. In addition, the risk of stent thrombosis was also found to be lower in provisional stent approach groups ${ }^{5,6}$. In this regard, the provisional one-stent approach has been preferred in the treatment of LM bifurcation stenosis ${ }^{7}$. In fact, in real-world practice, more than $60 \%$ of patients with LM bifurcation were treated using the provisional one-stent technique ${ }^{4}$. Table 1 summarises the published studies reporting the clinical results of the provisional one-stent technique versus the double stenting technique for the treatment of LM bifurcation. However, all the studies referred to above were observational studies. The Nordic-Baltic Bifurcation IV study, including non-LM bifurcation, suggested favourable results with the two-stent strategy over the one-stent strategy in large side branches, although statistical significance was not achieved. In addition, the worse outcome in the double stenting group might be associated with selection bias. Therefore, further large randomised controlled studies will be necessary for proper comparison of the provisional approach and the double stenting approach in LM bifurcation.

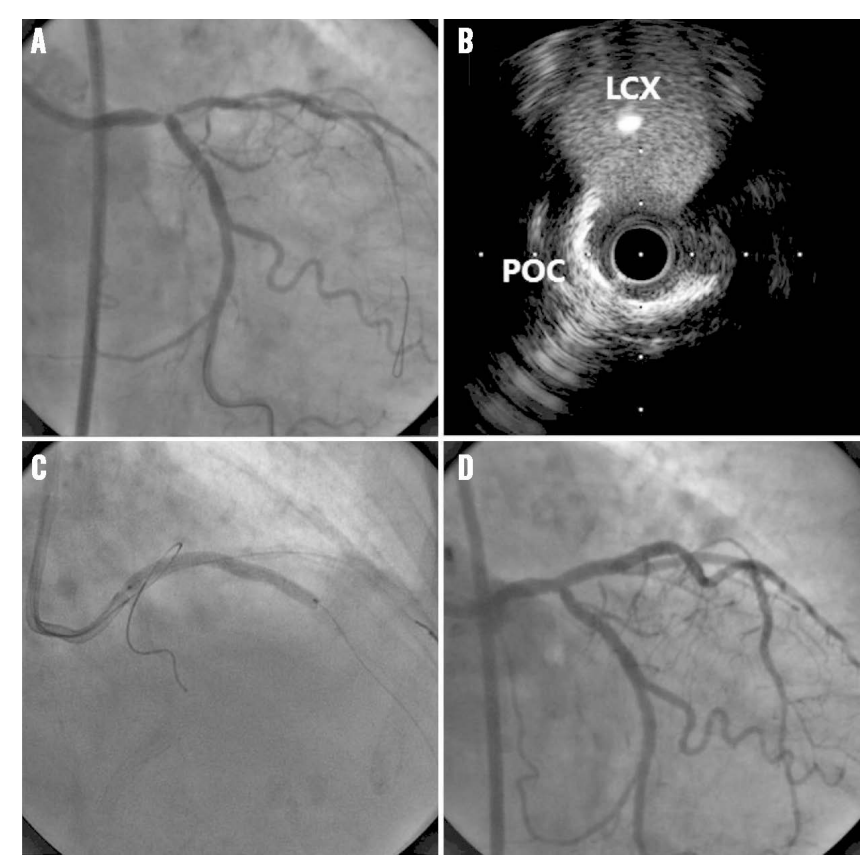

Figure 1. Provisional approach for distal left main stenosis. Coronary angiography showed true bifurcation (Medina 1,1,1) (A), but intravascular ultrasound revealed very minimal disease at the ostium of the left circumflex artery (B). Therefore, provisional one-stent implantation was performed $(C)$, and the final angiogram showed a successful result without side branch occlusion (D). POC: polygon of confluence

\section{How to select the provisional approach}

Due to the large jeopardised area of the left circumflex artery, the possibility of circulatory collapse after main vessel (MV) stenting should always be considered. The presence or absence of significant disease involvement of the LCX ostium was therefore defined as an important factor in selecting the provisional one-stent approach. LM bifurcation with insignificant ostial LCX stenosis or non-left dominant coronary system would be a favourable target for the provisional one-stent approach (Figure 2). In contrast, in case of significant ostial stenosis of the LCX with a left dominant coronary system,

Table 1. Outcomes of provisional stenting versus double stenting.

\begin{tabular}{|c|c|c|c|c|c|c|c|c|c|}
\hline \multirow[b]{2}{*}{ Study name } & \multirow[b]{2}{*}{ Year } & \multicolumn{2}{|c|}{ Patients, N } & \multirow{2}{*}{$\underset{(\mathrm{mo})}{\mathrm{FU}}$} & \multicolumn{5}{|c|}{ Adjusted hazard ratio (95\% confidence interval)* } \\
\hline & & $\begin{array}{l}\text { Provisional } \\
\text { approach }\end{array}$ & $\begin{array}{l}\text { Double } \\
\text { stenting }\end{array}$ & & MACE & Death or MI & Death & MI & TVR \\
\hline Palmerini3 & 2008 & 456 & 317 & 24 & $\begin{array}{c}0.48(0.33-0.69) \\
p=0.001\end{array}$ & $\begin{array}{c}0.38(0.17-0.85) \\
p=0.018\end{array}$ & - & - & - \\
\hline Toyofuku $^{6}$ & 2009 & 261 & 119 & 36 & - & - & $\begin{array}{c}0.61(0.34-1.08) \\
p=0.09\end{array}$ & - & $\begin{array}{c}0.32(0.18-1.21) \\
p<0.01\end{array}$ \\
\hline $\mathrm{Kim}^{4}$ & 2011 & 234 & 158 & 36 & $\begin{array}{c}0.89(0.22-0.67) \\
p<0.001\end{array}$ & - & $\begin{array}{c}0.77(0.28-2.13) \\
p=0.62\end{array}$ & $\begin{array}{c}0.38(0.19-0.78) \\
p=0.008\end{array}$ & $\begin{array}{c}0.16(0.05-0.57) \\
p=0.005\end{array}$ \\
\hline Song ${ }^{5}$ & 2014 & 509 & 344 & 36 & $\begin{array}{c}0.42(0.28-0.63) \\
p<0.001\end{array}$ & $\begin{array}{c}0.48(0.25-0.93) \\
p=0.03\end{array}$ & $\begin{array}{c}0.30(0.11-0.81) \\
p=0.02\end{array}$ & $\begin{array}{c}0.41(0.18-0.95) \\
p=0.04\end{array}$ & $\begin{array}{c}0.47(0.32-0.69) \\
p<0.01\end{array}$ \\
\hline
\end{tabular}

*Hazard ratios are for patients receiving the provisional approach, as compared with patients receiving double stenting. FU: follow-up; MACE: major adverse cardiac events; MI: myocardial infarction; mo: months; TVR: target vessel revascularisation 


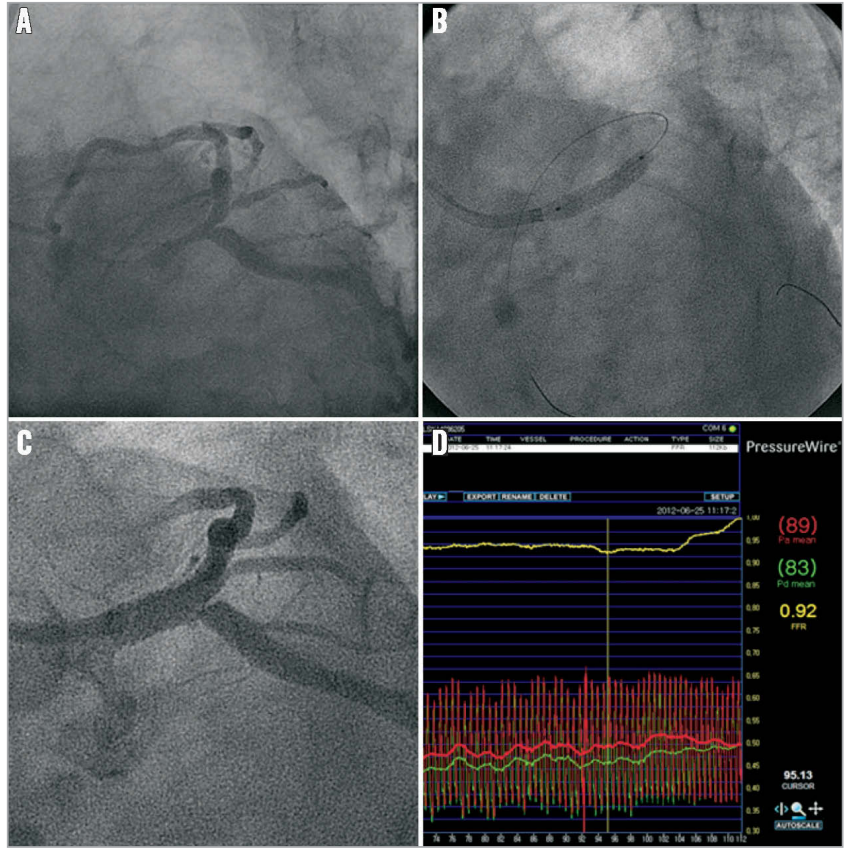

Figure 2. Fractional flow measurement after main vessel stenting. For LM bifurcation disease (A), provisional one-stent implantation was performed (B). After main vessel stenting, angiographically significant stenosis was observed at the ostium of left circumflex artery (C). However, fractional flow reserve was 0.92 (functionally insignificant stenosis) (D), therefore an additional procedure could be avoided.

the double-stent technique should be performed. When the ostium of the left anterior descending artery (LAD) is not diseased, provisional one-stent implantation can be used by inserting the LM stent towards the LCX. Table 2 summarises some suggestions for the selection criteria on which the LM bifurcation stenting strategy could be based. In addition, the bifurcation angle should be considered to prevent the occlusion of the side branch and to improve outcomes ${ }^{8}$.

As intravascular ultrasound (IVUS), particularly direct imaging from the LCX, provides more accurate information of the disease status of the distal LM complex including the LCX ostium,

Table 2. Selection criteria for the provisional approach.

\begin{tabular}{|l|l|}
\hline \multicolumn{1}{|c|}{ Strategy } & \multicolumn{1}{c|}{ Anatomical features } \\
\hline $\begin{array}{l}\text { Favour } \\
\text { provisional } \\
\text { approach }\end{array}$ & $\begin{array}{l}\text { - Insignificant stenosis at the ostial LCX with Medina classification } \\
1,1,0 \text { or } 1,0,0 \\
- \text { Small } L C X<2.5 \mathrm{~mm} \text { in diameter } \\
\end{array}$ \\
& - Diminutive LCX, right dominant coronary system \\
& - Wide angle between LAD and LCX \\
& - No concomitant disease or only focal disease in LCX \\
\hline Favour & - Significant stenosis at the ostial LCX with Medina classification \\
two-stent & $1,1,1$ or $1,0,1$ or $0,1,1$ \\
technique & - Large LCX $\geq 2.5$ mm in diameter \\
& - Diseased left dominant coronary system \\
& - Narrow angle between LAD and LCX \\
& - Concomitant diffuse disease in LCX \\
\hline
\end{tabular}

pre-procedural IVUS is very helpful in the selection of a more appropriate and safer stenting strategy. Previous studies have reported that the use of IVUS reduced the risk of side branch (SB) occlusion after MV stenting 9 . In addition, IVUS-guided PCI for LM disease was associated with lower mortality in LM PCI with drug-eluting stents ${ }^{10}$. Kang et al reported that an IVUS-derived minimal lumen of $>3.7 \mathrm{~mm}^{2}$ or plaque burden of $<56 \%$ in the LCX ostium can exclude functional SB compromise (fractional flow reserve $<0.80$ ) after MV stenting in LM bifurcation treatment $^{11}$. In addition, plaque distribution in the carina side ${ }^{12}$ and the presence of calcified plaque ${ }^{13}$ should be considered in order to avoid SB compromise after MV stenting.

\section{How to decide on the side branch intervention}

If patients have ischaemic symptoms or signs after MV stenting, further SB intervention should be performed. However, in case of asymptomatic angiographic stenosis of the SB ostium, SB interventions after MV stenting are frequently performed due to the large ischaemic burden of the LCX, although it remains unclear whether treating these lesions by using complex interventional strategies will show clinical advantages.

Two small pilot studies suggested the benefit of fractional flow reserve (FFR)-guided decision making for SB intervention after MV stenting in LM bifurcation ${ }^{11,14}$. Similar to the non-LM bifurcation, they revealed discrepancies between angiographic stenosis and FFR data (Figure 2). Only less than one third of angiographically jailed LCX ostia have functionally significant stenosis (FFR <0.80). Therefore, the use of an FFR-guided PCI strategy to treat the jailed LCX reduced the need for additional SB intervention and associated procedure-related complications. However, long-term clinical studies in a large-sized population should be conducted to validate this FFR-guided SB approach in LM bifurcation.

\section{Technical considerations WIRING}

Based on our experiences, placing a wire in the LCX before MV stenting is usually needed, particularly in cases with: 1) narrowing at the LCX ostium, 2) severe stenosis of the main branch having a large plaque burden at risk of plaque shift, 3) narrow angle of the LCX origination, and 4) deterioration of the LCX ostium after predilation of the main branch. Since side branch compromise may occur unpredictably, a side branch wire should be left until the procedure on the MV has been completed. The jailed wire in the side branch can act as a marker of the occluded SB and straighten the angle between the SB and the MV to facilitate further access.

When further treatment of the SB is necessary, rewiring through the distal strut (close to the carina) following the MV stenting is strongly recommended since it creates better SB scaffolding compared to proximal wire crossing, although it might be difficult to achieve in clinical practice based on angiography only. 


\section{STENT SIZE SELECTION AND PROXIMAL OPTIMISATION TECHNIQUE}

Stent size selection for the one-stent technique in LM bifurcation is sometimes difficult due to size discrepancy between the proximal and the distal main branch. In general, the choice of stent size depends on the distal main vessel. In addition, the proximal part of the stent is then dilated using a larger balloon (proximal optimisation technique [POT]) to improve proximal main vessel stent apposition and to facilitate safe side branch guidewire recrossing via a distal stent strut ${ }^{15,16}$.

\section{SYSTEMATIC KISSING BALLOON INFLATION}

Systematic final kissing balloon inflation (FKB) after MV stenting was performed frequently in the provisional one-stent approach. However, the role of FKB was unclear. The ASAN MAIN Registry ${ }^{17}$ enrolled 413 patients receiving the provisional one-stent technique. Of these, 96 patients received FKB after MV stenting and 318 patients did not receive FKB. After MV stenting, only one patient suffered from SB branch occlusion (defined as less than TIMI 3 flow). During two-year follow-up, the rate of the composite of death, myocardial infarction, or target lesion revascularisation was not significantly different between groups regardless of angiographic SB stenosis (12.5\% in the FKB group and $8.5 \%$ in the non-FKB group, adjusted hazard ratio $1.10,95 \%$ confidence interval $0.49-2.49, \mathrm{p}=0.82)$. Furthermore, target vessel revascularisation occurred more frequently in the FKB group $(8.1 \%$ versus $4.8 \%$, adjusted hazard ratio 1.12 , 95\% confidence interval $0.40-3.11$, $\mathrm{p}=0.83$ ), although the difference was statistically insignificant ${ }^{17}$. Another small study also showed the same trends ${ }^{18}$. Therefore, systematic FKB after MV stenting in the provisional one-stent strategy may not be associated with better clinical outcomes. However, these studies are retrospective and observational. Therefore, it should be noted that the worse outcome after FKB could be due to the selection of more severe patients among patients receiving FKB. Further randomised controlled trials are necessary.

\section{BAIL-OUT DOUBLE STENTING}

If the operators decide to use the provisional approach, there is almost always the possibility of placing a second stent on the LCX in case the result is not optimal or adequate. The available stent bailout techniques are restricted to either T-stenting or culotte. In the case of T-stenting, there is an inherent risk of protrusion into the MB or gap at the side branch ostium. However, the T-stenting technique might provide better outcomes in LM than in non-LM bifurcations, since the LM angle is wide (nearly 90 degrees in a lot of cases), with less chance of leaving a gap than when the bifurcation angle is very narrow. The culotte technique also has the disadvantage of a double layer of stent struts in the proximal $\mathrm{MB}^{19}$. Double stenting techniques will be discussed in detail in another chapter ${ }^{20}$.

\section{OVERSTRETCHING: INSIGHTS FROM BENCHTOP STUDIES}

During LM stenting, overstretching of a coronary stent frequently occurred due to anatomical characteristics (large size of LM and the size discrepancy between proximal and distal vessels) and procedural factors (POT and kissing balloon inflation). A recent in vitro study showed that expansion of a stent to larger diameters is limited by its design model. Therefore, when post-dilatation with a larger balloon size is intended, knowing the cut-off diameters among the different existing design models is critical to optimise stent selection ${ }^{21}$. Inadvertent selection of a stent with only limited expansion capacity may lead to unpredictable results with grossly overstretched struts and a risk of incomplete apposition (Figure 3).

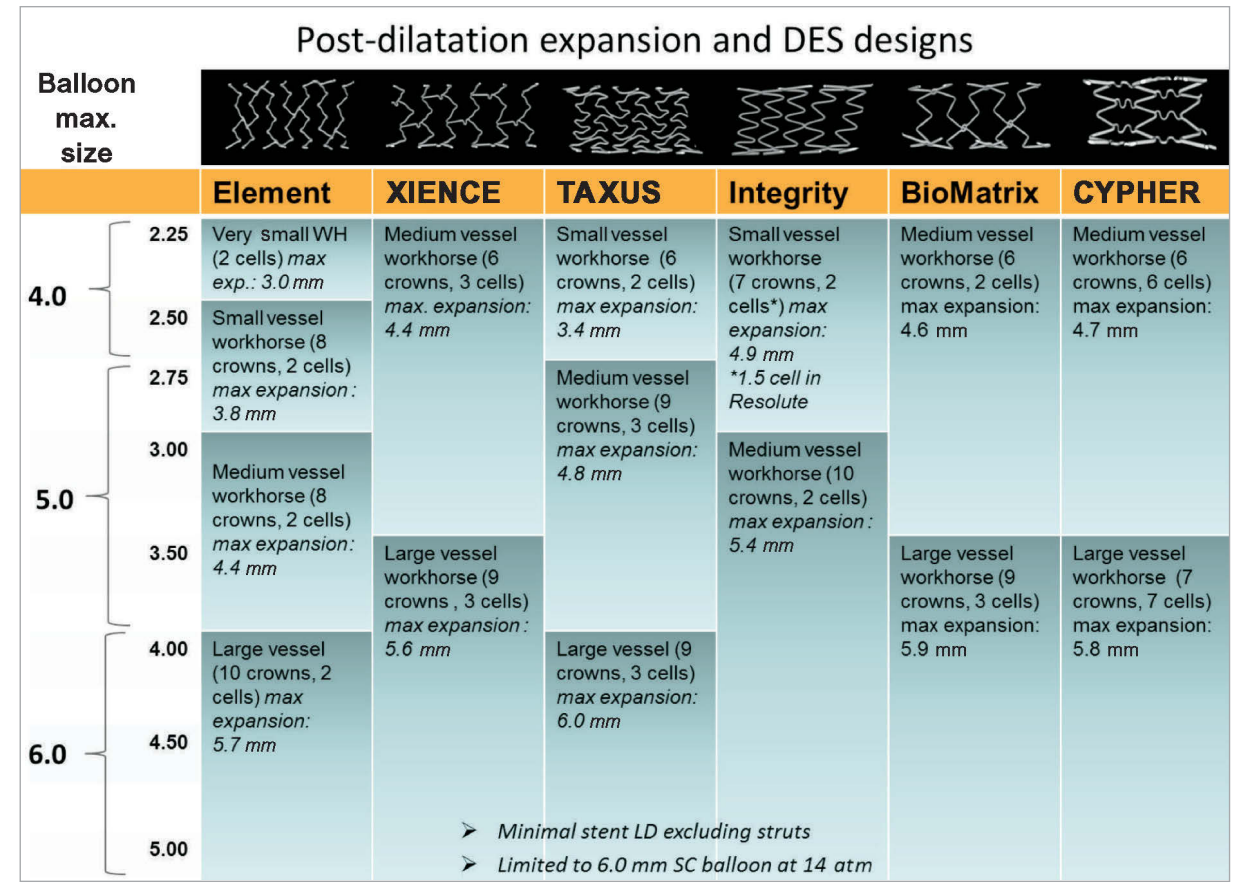

Figure 3. Expansion achieved for the different stent design models of six widely used drug-eluting stents. (Adapted from Foin et a ${ }^{21}$ ) 


\section{Conclusions}

We propose a scheme summarising how to select and perform the provisional approach for LM bifurcation in Figure 4. Careful selection of a potential candidate for the provisional approach is the most important step to take in order to avoid procedure-related complications. Meticulously performed IVUS evaluation plays a helpful role in the proper selection of this strategy and in achieving optimal stent results. In addition,
FFR measurement can lead to the avoidance of unnecessary SB interventions.

\section{Conflict of interest statement}

The authors have no conflicts of interest to declare.

\section{References}

The references can be found in the online version of the paper.

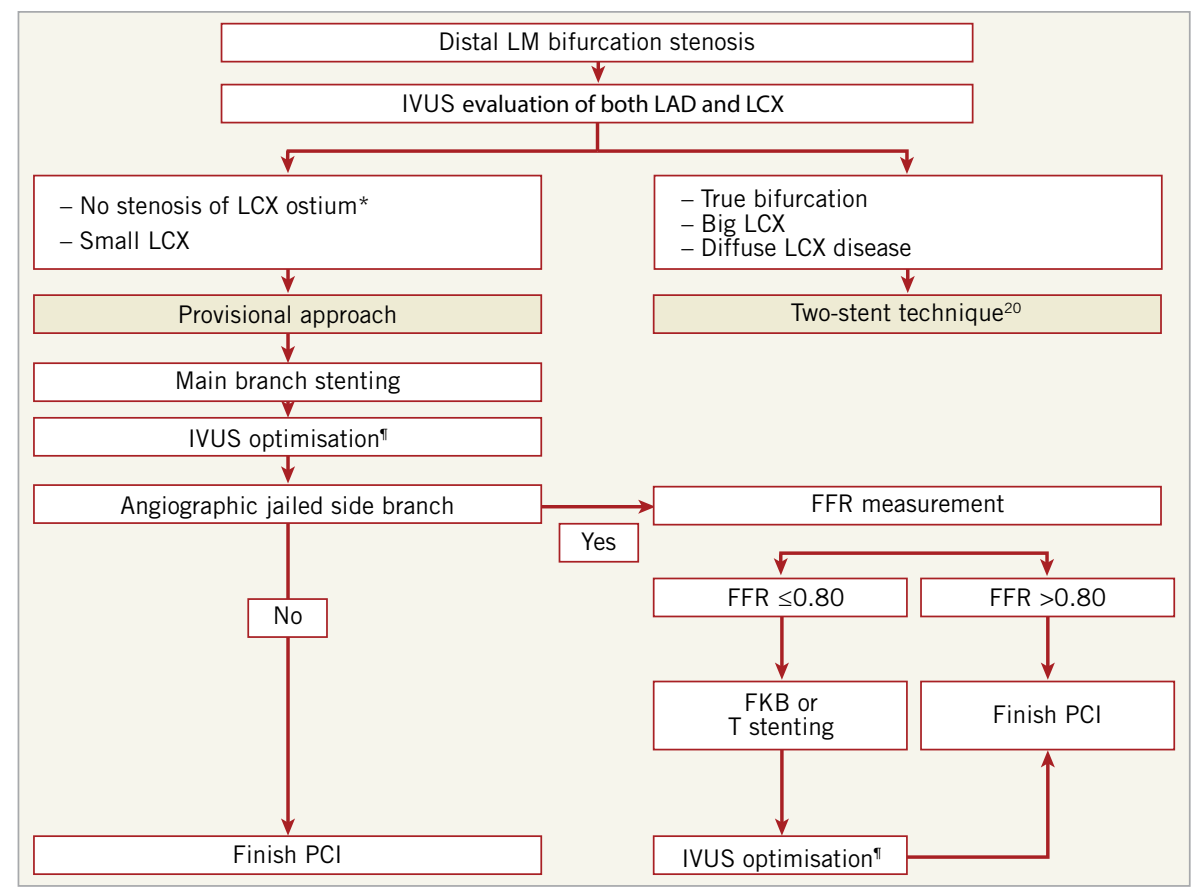

Figure 4. Summary of how to choose the provisional approach for distal left main bifurcation lesions. *In general, minimal lumen area $>4 \mathrm{~mm}^{2}$ or plaque burden $<50 \%$ of ostium of left circumflex artery was considered to be insignificant disease. "The stent should be well apposed to the vessel wall and sufficiently expanded to avoid restenosis (minimal stent area of $5 \mathrm{~mm}^{2}$ for ostium of left circumflex artery, $6 \mathrm{~mm}^{2}$ for proximal left anterior descending artery, $7 \mathrm{~mm}^{2}$ for polygon of confluence, and $8 \mathrm{~mm}^{2}$ for distal left main), without procedurerelated complication. FKB: final kissing balloon; IVUS: intravascular ultrasound; LAD: left anterior descending artery; LCX: left circumflex artery; LM: left main; PCI: percutaneous coronary intervention 


\section{Online data supplement}

\section{References}

1. Authors/Task Force members, Windecker $\mathrm{S}$, Kolh $\mathrm{P}$, Alfonso F, Collet JP, Cremer J, Falk V, Filippatos G, Hamm C, Head SJ, Jüni P, Kappetein AP, Kastrati A, Knuuti J, Landmesser U, Laufer G, Neumann FJ, Richter DJ, Schauerte P, Sousa Uva M, Stefanini GG, Taggart DP, Torracca L, Valgimigli M, Wijns W, Witkowski A. 2014 ESC/EACTS Guidelines on myocardial revascularization. EuroIntervention. 2015;10:1024-94.

2. Naganuma T, Chieffo A, Meliga E, Capodanno D, Park SJ, Onuma Y, Valgimigli M, Jegere S, Makkar RR, Palacios IF, Costopoulos C, Kim YH, Buszman PP, Chakravarty T, Sheiban I, Mehran R, Naber C, Margey R, Agnihotri A, Marra S, Capranzano P, Leon MB, Moses JW, Fajadet J, Lefevre T, Morice MC, Erglis A, Tamburino C, Alfieri O, Serruys PW, Colombo A. Long-term clinical outcomes after percutaneous coronary intervention for ostial/ mid-shaft lesions versus distal bifurcation lesions in unprotected left main coronary artery: the DELTA Registry (drug-eluting stent for left main coronary artery disease): a multicenter registry evaluating percutaneous coronary intervention versus coronary artery bypass grafting for left main treatment. JACC Cardiovasc Interv. 2013;6:1242-9.

3. Palmerini T, Marzocchi A, Tamburino C, Sheiban I, Margheri M, Vecchi G, Sangiorgi G, Santarelli A, Bartorelli A, Briguori C, Vignali L, Di Pede F, Ramondo A, Inglese L, De Carlo M, Falsini G, Benassi A, Palmieri C, Filippone V, Sangiorgi D, Barlocco F, De Servi S. Impact of bifurcation technique on 2-year clinical outcomes in 773 patients with distal unprotected left main coronary artery stenosis treated with drug-eluting stents. Circ Cardiovasc Interv. 2008;1:185-92.

4. Kim WJ, Kim YH, Park DW, Yun SC, Lee JY, Kang SJ, Lee SW, Lee CW, Park SW, Park SJ. Comparison of single- versus two-stent techniques in treatment of unprotected left main coronary bifurcation disease. Catheter Cardiovasc Interv. 2011;77:775-82.

5. Song YB, Hahn JY, Yang JH, Choi SH, Choi JH, Lee SH, Jeong MH, Kim HS, Lee JH, Yu CW, Rha SW, Jang Y, Yoon JH, Tahk SJ, Seung KB, Oh JH, Park JS, Gwon HC. Differential prognostic impact of treatment strategy among patients with left main versus non-left main bifurcation lesions undergoing percutaneous coronary intervention: results from the COBIS (Coronary Bifurcation Stenting) Registry II. JACC Cardiovasc Interv. 2014;7: 255-63.

6. Toyofuku M, Kimura T, Morimoto T, Hayashi Y, Ueda H, Kawai K, Nozaki Y, Hiramatsu S, Miura A, Yokoi Y, Toyoshima S, Nakashima H, Haze K, Tanaka M, Take S, Saito S, Isshiki T, Mitsudo K; j-Cypher Registry Investigators. Three-year outcomes after sirolimus-eluting stent implantation for unprotected left main coronary artery disease: insights from the j-Cypher registry. Circulation. 2009;120:1866-74.

7. Lassen JF, Holm NR, Stankovic G, Lefevre T, Chieffo A, Hildick-Smith D, Pan M, Darremont O, Albiero R, Ferenc M,
Louvard Y. Percutaneous coronary intervention for coronary bifurcation disease: consensus from the first 10 years of the European Bifurcation Club meetings. EuroIntervention. 2014;10:545-60.

8. Girasis C, Farooq V, Diletti R, Muramatsu T, Bourantas CV, Onuma Y, Holmes DR, Feldman TE, Morel MA, van Es GA, Dawkins KD, Morice MC, Serruys PW. Impact of 3-dimensional bifurcation angle on 5-year outcome of patients after percutaneous coronary intervention for left main coronary artery disease: a substudy of the SYNTAX trial (synergy between percutaneous coronary intervention with taxus and cardiac surgery). JACC Cardiovasc Interv. 2013;6:1250-60.

9. Hahn JY, Chun WJ, Kim JH, Song YB, Oh JH, Koo BK, Rha SW, Yu CW, Park JS, Jeong JO, Choi SH, Choi JH, Jeong MH, Yoon JH, Jang Y, Tahk SJ, Kim HS, Gwon HC. Predictors and outcomes of side branch occlusion after main vessel stenting in coronary bifurcation lesions: results from the COBIS II Registry (COronary BIfurcation Stenting). J Am Coll Cardiol. 2013;62: 1654-9.

10. Park SJ, Kim YH, Park DW, Lee SW, Kim WJ, Suh J, Yun SC, Lee CW, Hong MK, Lee JH, Park SW; MAIN-COMPARE Investigators. Impact of intravascular ultrasound guidance on longterm mortality in stenting for unprotected left main coronary artery stenosis. Circ Cardiovasc Interv. 2009;2:167-77.

11. Kang SJ, Ahn JM, Kim WJ, Lee JY, Park DW, Lee SW, Kim YH, Lee CW, Park SW, Park SJ. Functional and morphological assessment of side branch after left main coronary artery bifurcation stenting with cross-over technique. Catheter Cardiovasc Interv. 2014;83:545-52.

12. Yoshitaka Goto Y, Kawasaki T, Koga N, Tanaka H, Koga H, Orita Y, Ikeda S, Shintani Y, Kajiwara M, Fukuyama T. Plaque distribution patterns in left main trunk bifurcations: prediction of branch vessel compromise by multidetector row computed topography after percutaneous coronary intervention. EuroIntervention. 2012;8:708-16.

13. Sato K, Naganuma $T$, Costopoulos C, Takebayashi $H$, Goto K, Miyazaki T, Yamane H, Hagikura A, Kikuta Y, Taniguchi M, Hiramatsu S, Latib A, Ito H, Haruta S, Colombo A. Calcification analysis by intravascular ultrasound to define a predictor of left circumflex narrowing after cross-over stenting for unprotected left main bifurcation lesions. Cardiovasc Revasc Med. 2014;15:80-5.

14. Nam CW, Hur SH, Koo BK, Doh JH, Cho YK, Park HS, Yoon HJ, Kim H, Chung IS, Kim YN, Fearon WF, Tahk SJ, Kim KB. Fractional flow reserve versus angiography in left circumflex ostial intervention after left main crossover stenting. Korean Circ J. 2011;41:304-7.

15. Mylotte D, Routledge H, Harb T, Garot P, Hovasse T, Benamer H, Unterseeh T, Chevalier B, Morice MC, Louvard Y, Lefevre T. Provisional side branch-stenting for coronary 
bifurcation lesions: evidence of improving procedural and clinical outcomes with contemporary techniques. Catheter Cardiovasc Interv. 2013;82:E437-45.

16. Stankovic G, Lefevre T, Chieffo A, Hildick-Smith D, Lassen JF, Pan M, Darremont O, Albiero R, Ferenc M, Finet G, Adriaenssens T, Koo BK, Burzotta F, Louvard Y; European Bifurcation Club. Consensus from the 7th European Bifurcation Club meeting. EuroIntervention. 2013;9:36-45.

17. Park SJ, Ahn JM, Park HS, Cheon SS, Kim MS, Roh JH, Park HW, Chang M, Yoon SH, Lee JY, Park DW, Kang SJ, Lee SW, Kim YH, Lee CW, Park SW. TCT-234 Is Final Kissing Ballooning Mandatory in the Treatment of Distal Left Main Disease Treated by Simple Cross Over Stenting? J Am Coll Cardiol. 2014;64(11_S).

18. Rha SW, Elnagar A, Choi SY, Choi BG, Im SI, Kim S, Na JO, Han SW, Choi CU, Lim HE, Kim JW, Kim EJ, Seo HS,
Park CG, Oh DJ. AS-174 Role of Final Kissing Balloon for Unprotected Distal Left Main Bifurcation Intervention with Single Stent Strategy. Am J Cardiol. 2012;109: S86-7.

19. Grundeken MJ, Stella PR, Wykrzykowska JJ. Why the provisional single-stent approach is not always the right strategy; arguments for the development of dedicated bifurcation devices. EuroIntervention. 2012;7:1249-53.

20. Kim YH, Lassen JF, Hildick-Smith D. When is a two-stent technique needed and which technique should then be used for bifurcation coronary lesions? EuroIntervention. 2015;11 Suppl $\mathrm{V}: \mathrm{V} 96-8$.

21. Foin N, Sen S, Allegria E, Petraco R, Nijjer SS, Francis DP, Di Mario C, Davies JE. Maximal expansion capacity with current DES platforms: a critical factor for stent selection in the treatment of left main bifurcations? EuroIntervention. 2013;8:1315-25. 